\title{
$\beta$-Arrestin1 promotes the progression of chronic myeloid leukaemia by regulating BCR/ABL H4 acetylation
}

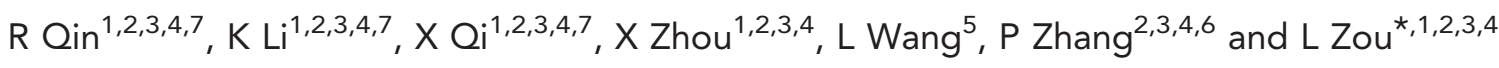

${ }^{1}$ Center for Clinical Molecular Medicine, Children's Hospital, Chongqing Medical University, Chongqing 400014, China; ${ }^{2}$ Department of Laboratory Medicine, Children's Hospital, Chongqing Medical University, Chongqing 400014, China; ${ }^{3}$ Ministry of Education Key Laboratory of Child Development and Disorders, Children's Hospital, Chongqing Medical University, Chongqing 400014, China; ${ }^{4}$ Key Laboratory of Pediatrics in Chongqing, Children's Hospital, Chongqing Medical University, Chongqing 400014, China; ${ }^{5}$ Chongqing Stem Cell Therapy Engineering Technique Center, Children's Hospital, Chongqing Medical University, Chongqing 400014, China and 'Hematological Department, The First Affiliated Hospital of Chongqing Medical University, Chongqing 400016, China

Background: $\beta$-Arrestins are scaffold proteins that interact with various cellular signals. Although $\beta$-arrestin2 mediates the initiation and progression of myeloid leukaemia, the critical role of $\beta$-arrestin 1 in the chronic myeloid leukaemia (CML) is still unknown. The aim of this study is to investigate the essential function of $\beta$-arrestin 1 in $\mathrm{CML}$

Methods: The expressions of $\beta$-arrestin1 and BCR/ABL in CML patients, animal models and K562 cells were measured by RT-PCR, immunofluorescence and western blotting. The effect of $\beta$-arrestin1 on CML animal models and K562 cells by colony formation, MTT and survival analysis were assessed. BCR/ABL H4 acetylation was analysed through the use of Chromatin-immunoprecipitation (ChIP) -on-chip and confirmed by ChIP respectively. Co-immunoprecipitation and confocal were examined for the binding of $\beta$-arrestin1 with enhancer of zeste homologue 2 (EZH2).

Results: The higher expression of $\beta$-arrestin 1 is positively correlated with clinical phases of CML patients. Depletion of $\beta$-arrestin 1 decelerates progression of K562 and primary cells, and increases survival of CML mice. Importantly, silenced $\beta$-arrestin 1 results in the decrease of $\mathrm{BCR} / \mathrm{ABL} \mathrm{H} 4$ acetylation level in $\mathrm{K} 562$ cells. Further data illustrate that nuclear $\beta$-arrestin1 binds to EZH2 to mediate $\mathrm{BCR} / \mathrm{ABL}$ acetylation and thus regulates cell progression in K562 cells and the survival of CML mice.

Conclusions: Our findings reveal a novel function of $\beta$-arrestin1 binding to $\mathrm{EZH} 2$ to promote $\mathrm{CML}$ progression by regulating BCR/ABL H4 acetylation.

Chronic myeloid leukaemia (CML), a clonal disorder of hematopoietic stem cells, constitutes about $15 \%$ of adult leukaemia. Its clinical phases typically progresses over time from an early chronic phase (CP) through an accelerated phase (AP) and terminal blast crisis phase $(\mathrm{BC})$. The outcome of CML is positively correlated with the advanced clinical stages. The molecular hallmark of CML, $\mathrm{BCR} / \mathrm{ABL}$ fusion oncogene, resulting from the translocation between chromosomes 9 and 22, has a critical role in the pathogenesis of CML. In fact, BCR/ABL levels were increased during disease progression (Neviani et al, 2005).

$\beta$-Arrestins, including four superfamily members, are multifunctional adaptor and scaffold proteins (Lefkowitz and Whalen, 2004). Only $\beta$-arrestin 1 and $\beta$-arrestin 2 are ubiquitously expressed. The traditional function of $\beta$-arrestin proteins is to mediate the

\footnotetext{
*Correspondence: Professor L Zou; E-mail: zoulin74@hotmail.com
}

${ }^{7}$ These authors contributed equally to this work

Received 21 January 2014; revised 31 March 2014; accepted 15 May 2014; published online 17 June 2014 
desensitization and internalisation of $\mathrm{G}$ protein-coupled receptors (GPCRs) (Luttrell and Lefkowitz, 2002; Katanaev et al, 2005) and other seven transmembrane-spanning receptors in an agonistdependent manner (Lefkowitz and Shenoy, 2005). Emerging evidence has demonstrated that $\beta$-arrestin1 mediates cellular function in some solid tumours. The best known examples are prostate cancer (Lakshmikanthan et al, 2009), lung cancer (Raghuwanshi et al, 2008), breast cancer (Ge et al, 2004) ovarian cancer (Rosano et al, 2009) and others. Recently, although $\beta$-arrestin2 was reported to participate in the initiation and progression of myeloid leukaemia (Fereshteh et al, 2012), the critical role of $\beta$-arrestin1 in human haematological malignancies remains unresolved. More interestingly, $\beta$-arrestin 1 has the ability of nuclear translocation and histone $\mathrm{H} 4$ acetylation modification with the delta-opioid receptors activated (Kang et al, 2005). The acetylation status of histone $\mathrm{H} 4$ terminal tails is one component of chromatin remodelling and chromatin-based processes including gene expression (Brower-Toland et al, 2005). Several studies underscored histone $\mathrm{H} 4$ hyperacetylation associated with BCR/ $\mathrm{ABL}$ tyrosine kinase in vitro and in vivo and proceeding, at least in part. Histone $\mathrm{H} 4$ acetylation status, in particular at the BCR/ABL promoter, influences the rearranged gene transcription, supporting a role for epigenetic chromatin modifications in the expression of the causative gene for CML (Brusa et al, 2006). Therefore, we are curious whether $\beta$-arrestin1 could regulate the acetylation of $\mathrm{BCR} / \mathrm{ABL}$ in CML progression.

Covalent modifications of core histone tails including acetylation, methylation, phosphorylation, ADP-rybosilation and ubiquitination, determine the chromatin structure and create binding surfaces for protein recognition, such as the bromodomain for acetylated lysines and the chromodomain for methylated lysines, therefore dictate gene transcription rate. In particular, the acetylation at specific lysine residues of $\mathrm{H} 3$ and $\mathrm{H} 4$ histone $\mathrm{NH} 2$-terminal tails weakens electrostatic interactions that tether octamer tails to the DNA phosphate backbone and induces reversible chromatin decondensation required for DNA transcription, replication and recombination (Strahl and Allis, 2000). Covalent modification could be regulated by other factors. Among the pivotal regulators, enhancer of zeste homologue 2 (EZH2), a Polycomb Group (PcG) protein homologous to Drosophila enhancer of zeste, is involved in gene silencing (Kleer et al, 2003). EZH2 catalyses the addition of methyl groups to histone $\mathrm{H} 3$ at Lys 27 (H3K27) forming H3K27me3, the activated form of $\mathrm{H} 3 \mathrm{~K} 27$, in target gene promoters, leading to epigenetic silencing (Wei et al, 2011). EZH2 is reported to be over-expressed, amplified and with an altered localisation in lymphoma or acute myeloid leukaemia (AML) (Roman-Gomez et al, 2007; Strathdee et al, 2007). However, whether EZH2 is involved in CML is largely unknown.

Herein, we revealed that enhanced $\beta$-arrestin 1 expression with the advanced clinical stages of CML patients, and depletion of $\beta$-arrestin 1 reduced the CML progression in vitro and in vivo, by regulating $\mathrm{BCR} / \mathrm{ABL} \mathrm{H} 4$ acetylation through binding to $\mathrm{EZH} 2$.

\section{MATERIALS AND METHODS}

Patients and samples. The use of human samples was approved by the Research Ethics Committee of Chongqing Medical University. All the patients involved in this study were admitted patients from haematological ward, and the nonmalignant haematological adult in-patient patients as the healthy control, from the First Affiliated Hospital of Chongqing Medical University who were diagnosed with clinically defined chronic myeloid leukaemia. All the information of patients is listed in Table 1.

\begin{tabular}{|c|c|c|c|c|c|c|}
\hline $\begin{array}{l}\text { Patient } \\
\text { no. }\end{array}$ & $\begin{array}{l}\text { Age } \\
(Y)\end{array}$ & $\begin{array}{c}\text { Gender } \\
(\mathrm{M} / \mathrm{F})\end{array}$ & $\begin{array}{c}\text { PB WBC } \\
\text { count } \\
\left(\times 10^{9} I^{-1}\right)\end{array}$ & $\begin{array}{c}\text { BM } \\
\text { blast } \\
\text { cell } \\
\text { count } \\
(\%)\end{array}$ & $\begin{array}{c}\text { BCR/ABL } \\
\text { fusion } \\
\text { gene }\end{array}$ & $\begin{array}{l}\text { Clinical } \\
\text { stages }\end{array}$ \\
\hline 1 & 28 & $F$ & 40.3 & 6.5 & + & $\mathrm{CP}$ \\
\hline 2 & 43 & $F$ & 36 & 5 & + & $\mathrm{CP}$ \\
\hline 3 & 38 & $M$ & 28.8 & 5.6 & + & $\mathrm{CP}$ \\
\hline 4 & 31 & $\mathrm{~F}$ & 70.4 & 7.8 & + & $\mathrm{CP}$ \\
\hline 5 & 47 & $\mathrm{~F}$ & 60.7 & 3.4 & + & $\mathrm{CP}$ \\
\hline 6 & 43 & $M$ & 56.7 & 6.8 & + & $\mathrm{CP}$ \\
\hline 7 & 32 & $\mathrm{~F}$ & 76.7 & 8.3 & + & $\mathrm{CP}$ \\
\hline 8 & 50 & $M$ & 39.4 & 5.5 & + & $\mathrm{CP}$ \\
\hline 9 & 40 & $F$ & 49.7 & 6.7 & + & $\mathrm{CP}$ \\
\hline 10 & 35 & $\mathrm{~F}$ & 60.3 & 7.1 & + & $\mathrm{CP}$ \\
\hline 11 & 23 & $M$ & 67.1 & 9 & + & $\mathrm{CP}$ \\
\hline 12 & 46 & $M$ & 41.2 & 5.9 & + & $\mathrm{CP}$ \\
\hline 13 & 48 & $\mathrm{~F}$ & 80.5 & 15.2 & + & AP \\
\hline 14 & 34 & M & 101.5 & 16.9 & + & $A P$ \\
\hline 15 & 36 & $\mathrm{~F}$ & 89.8 & 14.8 & + & $A P$ \\
\hline 16 & 50 & $\mathrm{~F}$ & 66.4 & 14.5 & + & $A P$ \\
\hline 17 & 51 & $\mathrm{~F}$ & 153.3 & 16.3 & + & $A P$ \\
\hline 18 & 32 & $M$ & 98 & 15.1 & + & $A P$ \\
\hline 19 & 39 & $M$ & 60.6 & 12.5 & + & $A P$ \\
\hline 20 & 36 & $F$ & 94.4 & 13 & + & AP \\
\hline 21 & 47 & $\mathrm{~F}$ & 160.2 & 71 & + & $B C$ \\
\hline 22 & 48 & $M$ & 150.3 & 60.9 & + & $B C$ \\
\hline 23 & 28 & $M$ & 108.9 & 61.4 & + & $B C$ \\
\hline 24 & 47 & $\mathrm{~F}$ & 405.3 & 81.2 & + & $B C$ \\
\hline 25 & 37 & $\mathrm{~F}$ & 190.6 & 78.6 & + & $B C$ \\
\hline 26 & 50 & $M$ & 98.4 & 57.7 & + & $B C$ \\
\hline
\end{tabular}

Bone marrow samples were obtained from the subjects. All patients completed and signed the informed consent form.

Antibodies, virus particles and reagents. Primary antibodies used were: mouse monoclonal anti- $\beta$-arrestin 1 , anti- $\beta$-arrestin2, anti- $\beta$-actin (Santa Cruz, Santa Cruz, CA, USA), anti-EZH2 (Cell Signaling, Danvers, MA, USA), rabbit monoclonal anti- $\beta$-arrestin1 (Abcam, Cambridge, MA, USA), anti-H3, anti-H3K27me3 (Cell Signaling), rabbit polyclonal anti-BCR (Santa Cruz) and as secondary antibodies for immunoprecipitation (IP) assays, goat anti-mouse or anti-rabbit conjugated with DyLight (Abcam). Antibodies against histone $\mathrm{H} 4$, acetyl-histone H4, acetyl-histone H4 (specific against acetylated Lys 12, Lys 16) were obtained from Upstate Biotechnology (Lake Placid, NY, USA). 3-deazaneplanocin A (DZNep), the inhibitor for EZH2, was purchased from Sigma (St Louis, MO, USA). All the $\beta$-arrestins related lentivirus package and control plasmid cDNAs were kindly gifted by Professor Gang Pei (Shi et al, 2007).

Cell culture and mice. The primary CML cells were isolated mononuclear cells from the newly diagnosed CML patients' bone marrow and then cultured in 10\% FBS IMEM. CML K562 and HEK293T cells (American Type Culture Collection, Manassas, 
MD, USA) were cultured and maintained in RPMI 1640 medium and DMEM (Gibco-BRL, Carlsbad, CA, USA). Lentivirus particles were produced by co-transfect HEK293T cells with the packaging and vector plasmids. Titres of all lentiviral vectors were determined by transducing HEK293T cells with serial dilutions of vector supernatants. After ultra-centrifugation, the lentivirus titres were $1-10 \times 10^{6}$ transducing units $\mathrm{ml}^{-1}\left(\mathrm{TU} \mathrm{ml}^{-1}\right)$. K562 cells were infected by the lentivirus particles, then followed limit dilution to obtain the stable cells.

Four-to-six-week-old NOD/SCID mice were obtained from the Laboratory Animal Centre of Chongqing Medical University. All mice were housed in an SPF barrier animal facility before used. After irradiated with $2 \mathrm{~Gy} \mathrm{X}$-ray in the Experimental Animal Centre of the Third Military Medical University, $1 \times 10^{7}$ stable cells (K562-Ctrl, K562-si $\beta 1, \mathrm{~K} 562-$ si $\beta 1+\beta 1$ ) cells were tail vein injected into lethally irradiated NOD/SCID mice. Then peripheral blood (PB) WBC number was dynamically counted and the mice survival curves were analysis. All animal studies using cell lines were approved by the Institutional Animal Care and Use Committee of Chongqing Medical University (Workman et al, 2010).

Soft agar colony assay. After infection, different $\mathrm{K} 562$ cells were cultured in a two-layer soft agar for 14 days at $37^{\circ} \mathrm{C}$ and $5 \% \mathrm{CO}_{2}$. Washed, single-cell suspension of cells were numerated and plated into 12-well flat-bottomed plates with a total of 2000 cells per well in a volume of $1000 \mu \mathrm{l}$ per well. After incubation, the colonies $(\geqslant 40$ cells for each) were counted. Experiments were performed triplicate at each point.

Real-time RT-PCR. Total RNA was extracted from cultured cells with TRIzol (Invitrogen, Carlsbad, CA, USA) according to the manufacturer's instructions. SuperScript II (Takara, Dalian, China) were used for reverse transcription of purified RNA. All gene transcripts were quantified by PCR with thermocycler (Bio-Rad, Hercules, CA, USA) using SYBR reagents (Takara, Dalian, China) according to the manufacturer's instructions. Primer pairs are listed in Table 2.

Western blotting. For western blotting (WB) analysis, cells were collected by centrifugation and lysed in RIPA buffer at $4{ }^{\circ} \mathrm{C}$. Total cell proteins were separated by sodium dodecyl sulphatepolyacrylamide gel electrophoresis (SDS-PAGE), blotted onto a PVDF membrane, immunoreacted with anti- $\beta$-arrestin1, anti$\beta$-arrestin 2 , anti-EZH2, anti-BCR/ABL or anti- $\beta$-actin antibodies and then reacted with secondary antibodies, developed image with enhanced chemiluminescence assay (Millipore, Bedford, MA, USA).

Co-immunoprecipitation. For co-immunoprecipitation (Co-IP) assays, whole cell lysates were first pre-cleared with normal IgG and protein A/G plus conjugated agarose beads (Santa Cruz), then incubated with anti-EZH2 antibody (Cell Signaling) or anti- $\beta$-arrestin1 (Santa Cruz) under gentle rocking at $4{ }^{\circ} \mathrm{C}$ overnight. Protein $\mathrm{A} / \mathrm{G}$ plus was added, and the mixture was incubated for further $4 \mathrm{~h}$ at $4{ }^{\circ} \mathrm{C}$. Following centrifugation, beads were washed five times with cold PBS and boiled in SDS-loading buffer. The samples were subjected to SDS-PAGE and western blotting analysis.

Immunofluorescence. For immunofluorescence (IF), cultured cells were washed three times in PBS, fixed with freshly prepared $4 \%$ formaldehyde in PBS for $15 \mathrm{~min}$ at room temperature, and subsequently permeabilized with $0.5 \%$ Triton X-100 for $5 \mathrm{~min}$, closed with goat serum for $30 \mathrm{~min}$ and incubated with diluted primary antibodies at $4{ }^{\circ} \mathrm{C}$ overnight. The next day, cells were incubated for $1 \mathrm{~h}$ with the appropriate secondary antibodies conjugated to DyLight. Finally, the specimens were analysed with laser-scanning confocal microscope (Leica, Beusheim, Germany).

Chromatin immunoprecipitation. Chromatin-immunoprecipitation (ChIP) assays were done according to the manufacturer's instruction (Upstate, NY, USA). The presence of the target gene promoter sequences in both the input DNA and the recovered DNA immunocomplexes was detected by quantitative PCR. All the data of quantitative PCR was normalised to those amplified DNA fragments of GAPDH. The levels of BCR/GAPDH or ABL/ GAPDH in control cells were viewed as 1.0 -fold. The primer pairs for specific promoter regions were from -1000 base pairs to approximately +500 base pairs of the transcription start site of the genes. Primer pairs are listed in Table 2.

ChIP-on-chip. ChIP was performed essentially as described previously. The immunoprecipitation DNA including input samples was amplified and labelled by using DSL method. The labelled DNA were dissolved in $80 \mu$ l total volume including $3 \times$ SSC, $0.2 \%$ SDS, $5 \times$ Denhart's, $25 \%$ formamide buffer, hybridised with ChIP-DSL H20K promoter array (Aviva, San Diego, CA, USA) overnight. The hybridised samples were scanned by LuxScan 10KA (CapitalBio, Beijing, China). The image profiling was performed and calculated by LuxScan 3.0 software and Molecule Annotation System (CapitalBio; Jia et al, 2013).

Statistical analysis. One-way ANOVAs were used to statistically analyse the difference among the CML clinical phase patients, and the multiple treatments for cells. And the paired $t$-test was used to compare the difference between cells with two treatments. Pearson analysis was performed to investigate the correlation of mRNA expression levels of $\mathrm{BCR} / \mathrm{ABL}$ and $\beta$-arrestin1. $P<0.05$ was considered statistical difference. Statistical analyses were performed using GraphPad Prism 5.0.

Table 2. Primer pairs for this whole manuscript

Forward primer $\left(5^{\prime}-3^{\prime}\right)$

Reverse primer $\left(3^{\prime}-5^{\prime}\right)$

Real-time RT-PCR

\begin{tabular}{|c|c|c|}
\hline $\begin{array}{l}\text { GAPDH } \\
\beta \text {-Arrestin1 } \\
\beta \text {-Arrestin2 } \\
\text { BCR/ABL }\end{array}$ & $\begin{array}{l}\text { AGAAGGTGGTGAAGCAGGCATC } \\
\text { CCTGGATGTCTTGGGTCTG } \\
\text { CAGCCAGGACCAGAGGACA } \\
\text { GACATGCCATAGGTAGCAATTTCCC }\end{array}$ & $\begin{array}{l}\text { CGGCATCGAAGGTGGAAGAGTG } \\
\text { TGATGGGTTCTCCGTGGTA } \\
\text { TGATAAGCCGCACAGAGTT } \\
\text { ACATCACGCCAGTCAACAGTCTGG }\end{array}$ \\
\hline \multicolumn{3}{|l|}{ ChIP } \\
\hline $\begin{array}{l}\text { GAPDH } \\
\text { ABL } \\
\text { BCR }\end{array}$ & $\begin{array}{l}\text { AGAAGGTGGTGAAGCAGGCATC } \\
\text { TCCAACCCTACTGCTCCCACC } \\
\text { CTGCGAGTTCTGCCAGAGAG }\end{array}$ & $\begin{array}{l}\text { CGGCATCGAAGGTGGAAGAGTG } \\
\text { ACCGCCGCCCCTCCCGGCTCTGGTC } \\
\text { CACCCTCCCCCCGTCCCTGT }\end{array}$ \\
\hline
\end{tabular}




\section{RESULTS}

Increased $\beta$-arrestin 1 expression promotes cell progression in CML cells. On the basis of our previous studies (Zou et al, 2008; Liu et al, 2011), we collected the bone marrow of CML patients in different clinical phases, including 12 cases of $\mathrm{CP}, 8$ cases of AP and 6 cases of BC (Table 1), and tested the expression of $\beta$-arrestin1 and $\beta$-arrestin 2 in mononuclear cells from these samples, respectively. The mononuclear cells from haematological nonmalignant patients $(n=10)$ were used as control. $\beta$-arrestin1 and $\beta$-arrestin 2 mRNA, protein expression were measured by realtime RT-PCR, compared with its respective inner control GAPDH to report the relative fold (Figure 1A), IF (Figure 1B and C) and WB (Figure 1D) with $\beta$-actin as reference, respectively. All the observations illustrated that both $\beta$-arrestin1 and $\beta$-arrestin2 expression were elevated in different clinical phases of CML patients, especially for $\beta$-arrestin1. Importantly, the elevated levels of $\beta$-arrestin 1 expression were positively correlated with the clinical phases of CML. The enhanced expression of $\beta$-arrestin1 and $\beta$-arrestin 2 were also confirmed by using the CML cell line, K562 (Figure 1E-G). The BCR/ABL expression levels were enhanced with the advanced clinical stages of CML (Figure $1 \mathrm{H}$ ), which was corresponding with the reports about BCR/ABL. Unexpectedly, the BCR/ABL level was positively correlated with $\beta$-arrestin1 (Figure 1I, $R^{2}=0.871$ ) rather than $\beta$-arrestin2 (data not shown). Altogether, we then focused on the role of $\beta$-arrestin1 in CML in subsequent studies.

To further determine the role of $\beta$-arrestin1 in CML progression, we over-expressed and gene-silenced $\beta$-arrestin 1 and $\beta$-arrestin 2 by transducing K562 cells with $\beta$-arrestin1 ( $\beta 1)$, $\beta$-arrestin2 ( $\beta 2), \beta$-arrestin1-siRNA (si $\beta 1)$ and $\beta$-arrestin2-siRNA (si $\beta 2)$ lentiviral particles, respectively. Transduction of K562 cells with nonspecific-siRNA lentiviral particles as control (Ctrl). Construction of $\beta 1$ siRNA, $\mathrm{pBS} / \mathrm{U} 6 / \beta 1$ siRNA and $\mathrm{pBS} / \mathrm{U6} /$ nonspecific siRNA plasmids were as described previously (Wang et al, 2003; Lu et al, 2011). The nucleotide sequences carried in the plasmids are 5'-GGAAGCTCAAGCACGAAGACAA-3' (siRNA
A

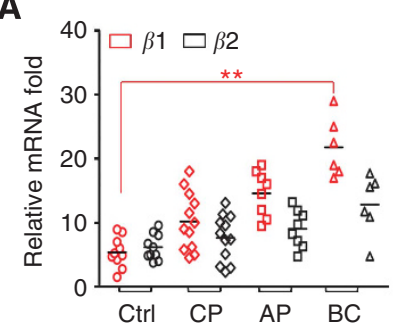

D

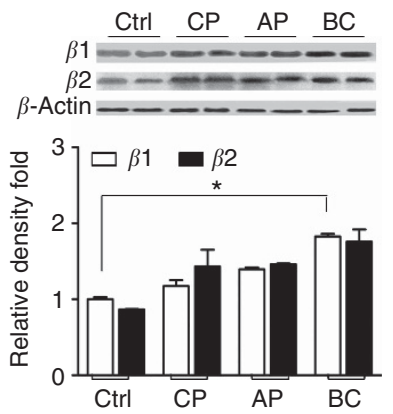

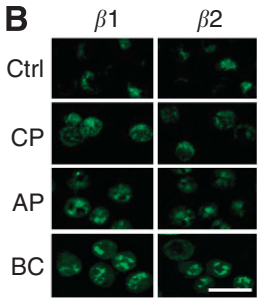

E

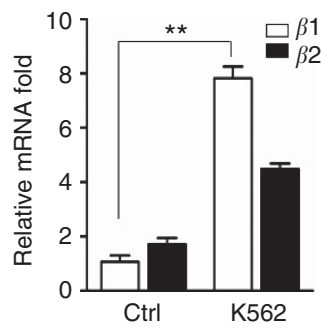

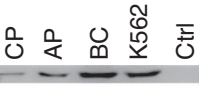
$\beta$-Actin $-1--$

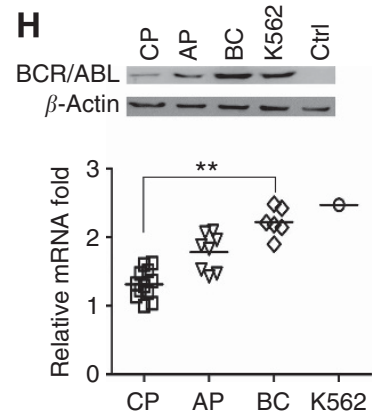

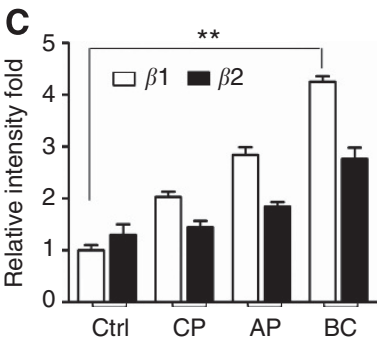

$\mathbf{F}$

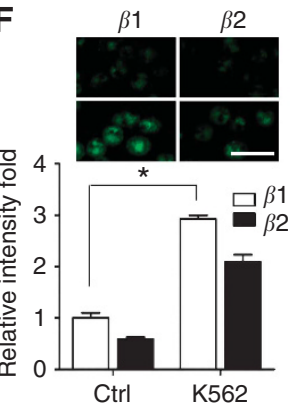

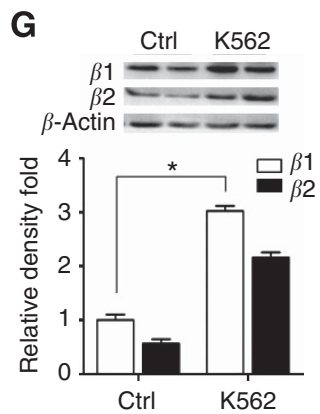

I

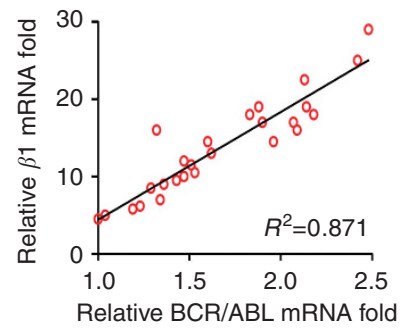

Figure 1. Expression of $\beta$-arrestin 1 and $B C R / A B L$ is enhanced in $C M L$ cells. The mRNA levels of $\beta$-arrestin 1 and 2 in (A) bone marrow cells of newly diagnosed CML patients in different clinical phases and (E) K562 cells were analysed by real-time RT-PCR. Representative figures of IF (B, F) and WB $(\mathbf{D}, \mathbf{G})$ of $\beta$-arrestin 1 and 2 expression levels in bone marrow cells of CML patients and K562 cells, scale bar, $10 \mu \mathrm{m}$. (C and F) The relative fluorescence intensity fold of $\beta$-arrestin 1 and $\beta$-arrestin 2 were quantified by NIS-Elements BR on Nikon software and the intensity of $\beta$-arrestin 1 in Ctrl was viewed as 1.0-fold. (D and G) The WB bands of $\beta$-arrestin 1 and 2 were quantified and normalised to $\beta$-actin by Bio-Rad Quantity-One software. (H)The mRNA levels of BCR/ABL in CML bone marrow cells and K562 cells were analysed by WB (upper panel) and RT-PCR (lower panel). All the data were calculated and normalised as fold change and the expression of $\beta$-arrestin1/GAPDH in Ctrl (haematological nonmalignant patients' cells as control) was viewed as 1.0-fold. The relative mRNA level of BCR/ABL was normalised with its corresponding GAPDH, and the mimimum relative mRNA level of CP group was viewed as 1.0-fold, and $\beta$-actin as loading control in WB. (I) The Pearson correlation analysis of $\mathrm{BCR} / \mathrm{ABL}$ and $\beta$-arrestin1 mRNA levels $\left(R^{2}=0.871\right)$ was performed by the use of GraphPad Prism 5.0. Data shown are means \pm s.d. of three independent experiments, ${ }^{*} P<0.05$ and ${ }^{\star \star} P<0.01$ vs the corresponding $\mathbf{C}$ trl. In $\mathbf{A}, \mathbf{C}, \mathbf{D}$ and $\mathbf{H},{ }^{\star} P<0.05$ and ${ }^{* \star} P<0.01$ among the groups, respectively. $\beta 1=\beta$-arrestin $1 ; \beta 2=\beta$-arrestin2. 

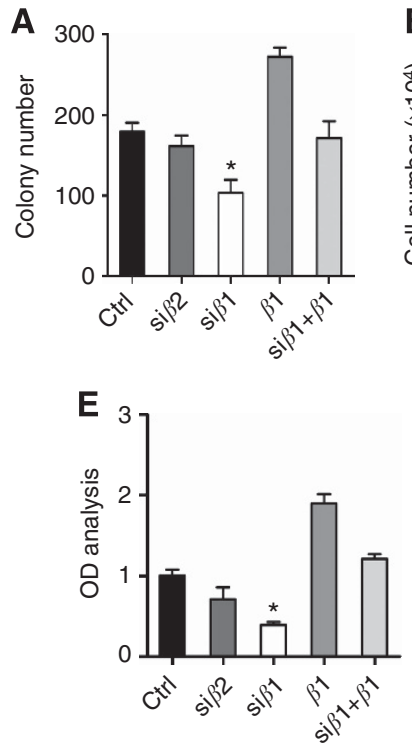
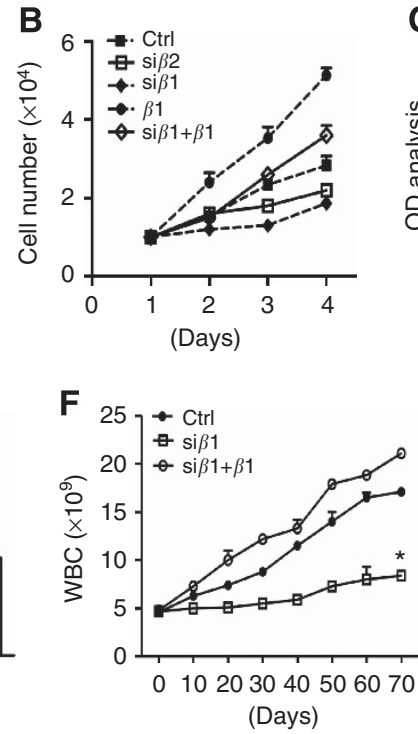
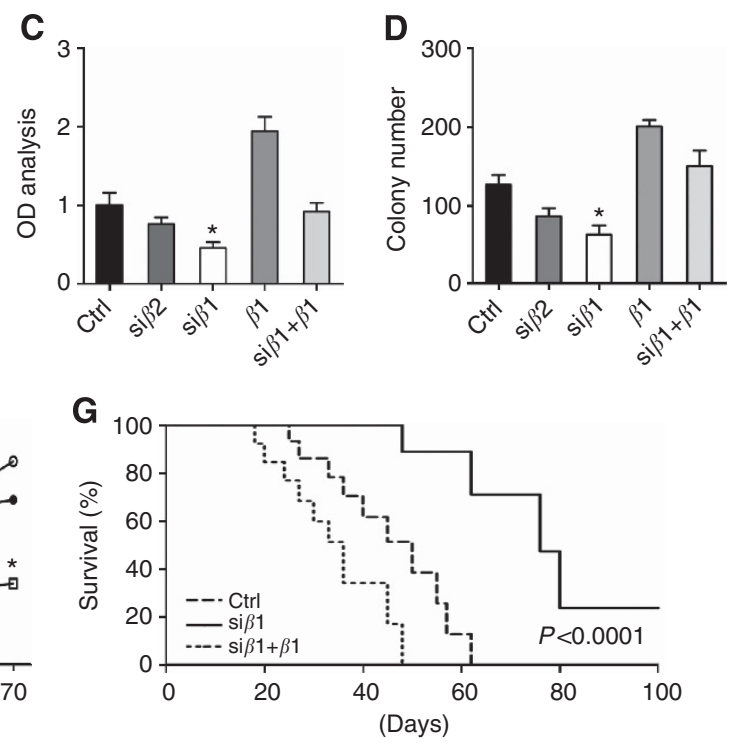

Figure 2. $\beta$-Arrestin1 promotes CML cells proliferation in vitro and in vivo. (A) Colony formation in soft agar, (B) cell counting and (C) MTT assay, shown through optical density (OD) value of $570 \mathrm{~nm}$ for 4 days in succession, were performed to analyse the cell proliferation of different stable K562 cells. (D) Colony formation and (E) MTT assay of transient transducing primary CML cells. Data shown are means \pm s.d. of three independent experiments, ${ }^{*} P<0.05$ vs Ctrl. (F) Dynamical PB WBC counting and (G) survival analysis of $C M L$ animal models, $n=10$ in each group. ${ }^{*} P<0.05$, $\star * P<0.01$ vs Ctrl.

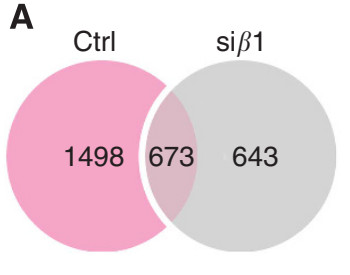

C

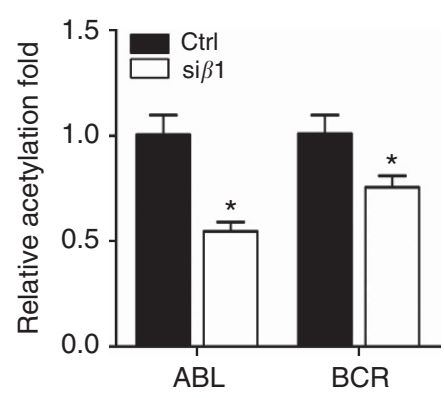

E

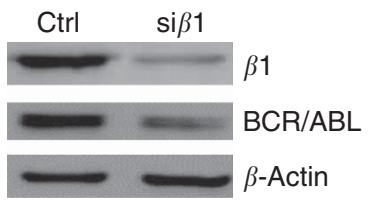

B
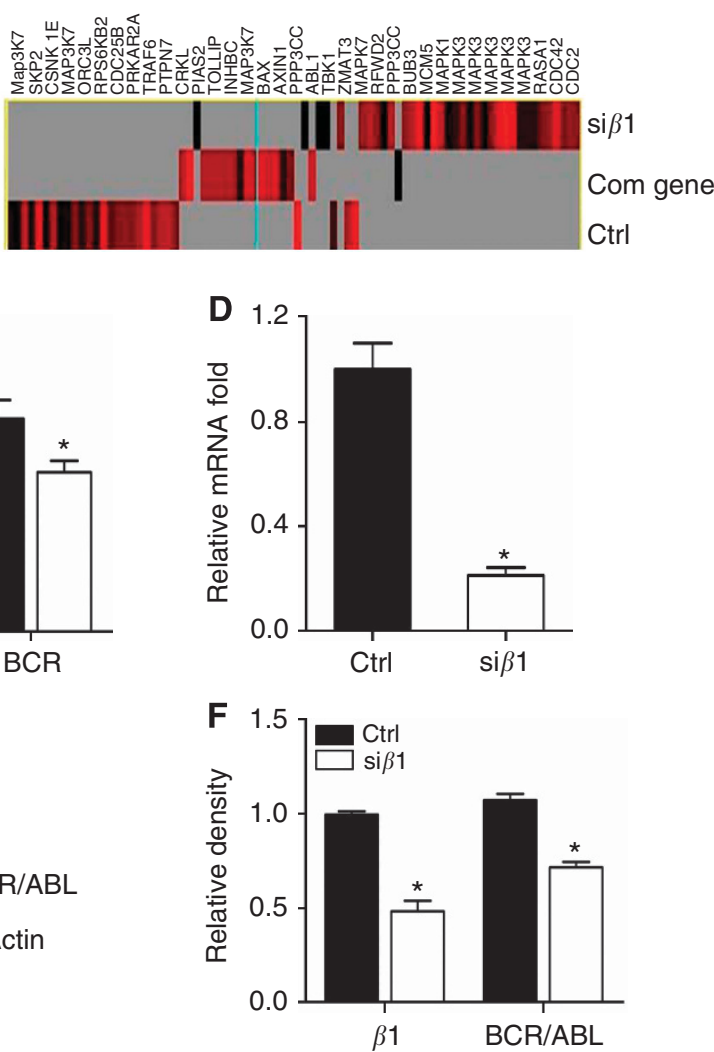

Figure 3. ChIP-on-chip analysis shows $\beta$-arrestin1 regulates $\mathrm{ABL}$ histone $\mathrm{H} 4$ acetylation and affects the expression of $B C R / A B L$ in $K 562$ cells. (A) The Venn diagrams show the number of $\beta$-arrestin 1 mediated histone $\mathrm{H} 4$ acetylation modification genes in the indicated K562 cells by using ChIP-on-chip analysis. (B) Cluster analysis show the target genes regulated by $\beta$-arrestin1. Rows represented the different stable K562 cells.

Columns represented the indicated signalling-related genes. The degree of colour saturation reflects the magnitude of acetylation. Black indicates hypoacetylation; red denotes hyperacetylation. (C) The acetylation alterations of BCR and ABL were confirmed by H4 ChIP in stable K562-si $\beta 1$ cells and K562-Ctrl cells. (D) BCR/ABL transcription levels were measured by real-time RT-PCR and normalised as folds with its respective GAPDH in the indicated stable K562-si $\beta 1$ (si $\beta 1$ ) and K562-Ctrl cells (Ctrl). (E) K562 cells expressing endogenous BCR/ABL was analysed by WB, and $\beta$-actin as the loading control. (F) The bands of BCR/ABL were quantified and normalised to $\beta$-actin by Bio-Rad Quantity-One software. And the data shown are the means \pm s.d. of three independent experiments. ${ }^{*} P<0.05$ vs $C$ trl. The full colour version of this figure is available at British Journal of Cancer online. 
A

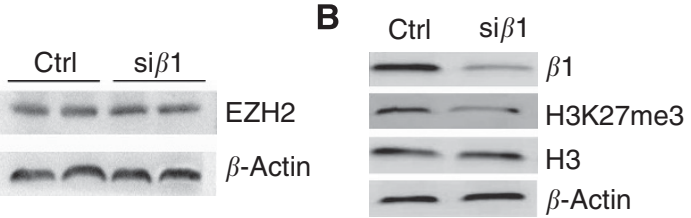

D
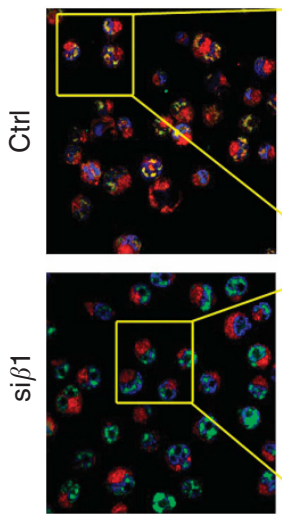
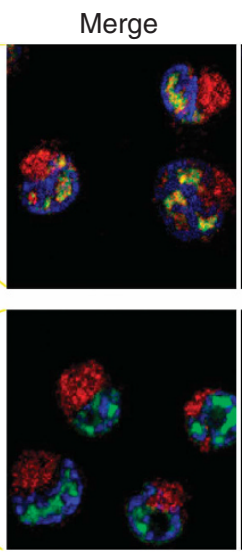

DAPI
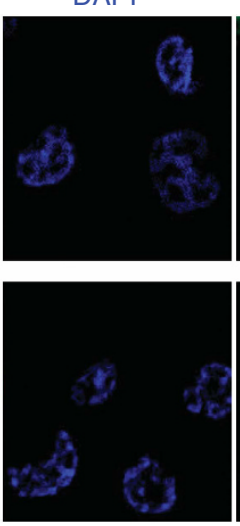

C

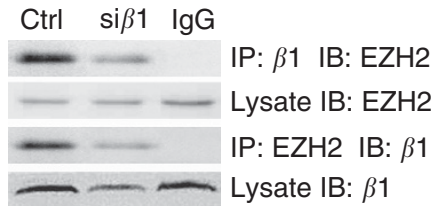

Figure 4. $\beta$-Arrestin1 interacts with EZH2 in the nucleus of $\mathrm{K} 562$ cells. (A) The expression of EZH2 in stable K562-si $\beta 1$ and K562-Ctrl cells was measured by WB with $\beta$-actin as the loading control. (B) The expression levels of H3K27me3 were analysed by WB, and H3 as the control. (C) K562 nuclear extracts were immunoprecipitated with EZH2 or $\beta$-arrestin1 antibody and the immunocomplexes were analysed in WB using antibodies against EZH2 or $\beta$-arrestin1. IgG as the negative control. (D) Confocal visualisation of EZH2 (green) and $\beta$-arrestin1 (red) in different stable $\mathrm{K} 562$ cells. And single confocal sections were shown. Scale bar, $5 \mu \mathrm{m}$. The full colour version of this figure is available at British Journal of Cancer online.

against both splicing isoforms of $\beta$-arrestin1 (Parruti et al, 1993). The stable transduced K562 cells were obtained by limited dilution and culture expansion. The expression of $\beta$-arrestin1 and $\beta$-arrestin 2 in stable $\mathrm{K} 562-\beta$-arrestin1 $(\beta 1), \mathrm{K} 562-\operatorname{si} \beta 1 \quad(\operatorname{si} \beta 1)$, K562- $\beta$-arrestin2 ( $\beta 2), \mathrm{K} 562$-si $\beta 2$ (si $\beta 2)$ and K562-Ctrl (Ctrl) cells were measured by real-time RT-PCR, IF and WB (Supplementary Figure S1) to verify the successful establishment for further experiments. The results from soft agar colony assay showed that over-expression of $\beta$-arrestin1 promoted K562 cells proliferation and progression, whereas silencing the $\beta$-arrestin 1 decreased the clone numbers. Markedly, the inhibition of K562 cell progression of $\operatorname{si} \beta 1$ could be rescued by $\beta 1$ (Figure $2 \mathrm{~A}$ ), further supporting the specificity of siRNA and functional conservation of this protein. Both the results from the colony formation assay (Figure $2 \mathrm{~A}$ ), cell growth curves (Figure 2B) and MTT assay (Figure 2C) showed that the growth of K562 cells was depressed when $\beta$-arrestin 1 was depleted. By contrast, the proliferation of K562 cells increased when $\beta$-arrestin 1 over-expressed, and $\beta$-arrestin 1 rescued its depletion. However, the alteration of clone formation, cell growth and proliferation were not significant alteration in K562 cells treated with si $\beta 2$ (Figure $2 \mathrm{~A}-\mathrm{C}$ ). Similar results were obtained from primary CML patient cells by transiently transducing them with $\beta 1, \beta 2$, si $\beta 1$, si $\beta 2$ or Ctrl lentiviral particles (Figure $2 \mathrm{D}$ and $\mathrm{E}$ ).

Subsequently, we first injected the stable K562-Ctrl and K562si $\beta 1$ cells into the tail vein of lethally irradiated NOD/SCID mice, and then injected $\beta 1$ lentiviral particles to rescue the effect of si $\beta 1$, to explore the function of $\beta$-arrestin 1 in $\mathrm{CML}$ in vivo. The $\mathrm{PB}$ WBC numbers of mice were dynamically counted and the survival curves were analysed. The results demonstrated that the $\mathrm{PB}$ WBC counts were decreased (Figure $2 \mathrm{~F}$ ) and the survival time was extended (Figure 2G) when $\beta$-arrestin1 was knocked down, and the effects could be rescued by $\beta$-arrestin1, indicating that $\beta$-arrestin1 has a crucial role in CML progression.

$\beta$-Arrestin1 regulates $\mathrm{BCR} / \mathrm{ABL}$ expression and $\mathrm{H} 4$ acetylation. Considering $\beta$-arrestin1 mediated $\mathrm{H} 4$ acetylation and regulated transcription of many genes (Kang et al, 2005), ChIP-on-chip for histone $\mathrm{H} 4$ acetylation of whole genome was used for screening the genes, which were regulated by $\beta$-arrestin1. The data from ChIPon-chip illustrated that $\beta$-arrestin1 mediated histone $\mathrm{H} 4$ acetylation of 1316 genes, including 673 common genes and 643 specific genes in stable K562-si $\beta 1$ cells, compared with those in K562-Ctrl cells (Figure 3A). Cluster analysis showed that histone $\mathrm{H} 4$ acetylation genes regulated by $\beta$-arrestin1 were predominantly involved in MAPK signalling, which was corresponding with the reports (Kang et al, 2005; Lefkowitz and Shenoy, 2005). Importantly, $\beta$-arrestin 1 regulates the acetylation of $\mathrm{ABL}$ gene (Figure 3B). To confirm these results, histone $\mathrm{H} 4$ acetylation status was assessed by labelling IP histone $\mathrm{H} 4$ with an anti-Ac-lys-12 and lys-16 antibody and IP chromatin with an anti-Ac-H4 antibody. Consistently, histone $\mathrm{H} 4$ of either ABL or BCR was hypoacetylated when $\beta$-arrestin 1 was knocked down (Figure $3 \mathrm{C}$ ). Here we focused on its role in BCR/ABL expression. Real-time RT-PCR, used to quantify $\mathrm{BCR} / \mathrm{ABL}$ transcript levels relative to the GAPDH gene, revealed a significant reduction in stable K562-si $\beta 1$ cells (Figure 3D). The results showed that BCR/ABL expression was also reduced in stable K562-si $\beta 1$ cells by subsequent WB analysis (Figure $3 \mathrm{E}$ and $\mathrm{F}$ ). These results demonstrated that $\beta$-arrestin1 could mediate histone $\mathrm{H} 4$ acetylation to further affect gene expression.

$\beta$-Arrestin 1 binds to $\mathrm{EZH} 2$ in nucleus to mediate BCR/ABL H4 acetylation and expression. $\beta$-Arrestin 1 regulates signal transduction and gene transcription mainly through protein-protein interaction (Kang et al, 2005). This prompted us to pay special attention to those factors critically involved in acetylation regulation, and finally selected EZH2, the critical PRC2 member. Among the components of PRC2, the EZH2 enzymatic activity is indispensable for PRC2-mediated gene silencing (Tang et al, 2009). By using Co-IP assay, we found that although there was no correlation between the expression of $\beta$-arrestin1 and EZH2 (Figure $4 \mathrm{~A}$ ), the interaction of $\beta$-arrestin 1 and $\mathrm{EZH} 2$ was obviously observed in stable K562-Ctrl cells by using both anti- $\beta$-arrestin1 and anti-EZH2 as immunoprecipitation (IP) reaction substrates 
(Figure $4 \mathrm{C}$ ). And the reduced $\beta$-arrestin1-EZH2 interaction was shown in stable K562-si $\beta 1$ cells with Co-IP assays (Figure $4 \mathrm{C}$ ). The expression of $\mathrm{H} 3 \mathrm{~K} 27 \mathrm{me} 3$, the activated form of $\mathrm{H} 3 \mathrm{~K} 27$, also decreased in K562-si $\beta 1$ stable cells (Figure 4B). The results from immunofluorescence confocal assay also confirmed that the binding of $\beta$-arrestin1-EZH2 in stable K562-Ctrl cells mainly existed in cell nucleus and nucleoli, and the most binding of $\beta$-arrestin 1 and EZH2 in nucleus was decreased in stable K562-si $\beta 1$ cells compared with those in K562-Ctrl cells (Figure 4D).

To investigate the necessity of $\beta$-arrestin1-EZH2 formation, further experiments carried on 3-deazaneplanocin A (DZNep), a small-molecule EZH2 inhibitor that disrupts PRC2 and manifests antitumour activity in a variety of cancers (Tan et al, 2007; Miranda et al, 2009; Momparler et al, 2012) to treat stable K562Ctrl cells, found that DZNep inhibited both the expression of $\mathrm{EZH} 2$ and the interaction of $\beta$-arrestin1-EZH2 without affecting the expression of $\beta$-arrestin1 (Figure 5A). Moreover, DZNep suppressed the cell growth of K562-Ctrl cells (Figure 5B), extended survival time of mice injected with K562-Ctrl cells through the tail vein (Figure 5C). Consistently, the histone $\mathrm{H} 4$ acetylation levels of BCR and ABL (Figure 5D) as well as expression of characteristic $\mathrm{BCR} / \mathrm{ABL}$ fusion gene (Figure $5 \mathrm{E}$ ) had also been repressed. Taken

together, these results provide evidence supporting that $\beta$-arrestin1 interacts with EZH2 to regulate $\mathrm{BCR} / \mathrm{ABL}$ acetylation and expression, and thus mediates CML progression.

\section{DISCUSSION}

$\beta$-Arrestin1 has critical roles in epigenetic regulation of gene transcription. In this study, we disclosed that $\beta$-arrestin1 is critically involved in CML progression. Importantly, $\beta$-arrestin 1 interacted with $\mathrm{EZH} 2$, and simultaneously mediated histone $\mathrm{H} 4$ acetylation of $\mathrm{BCR} / \mathrm{ABL}$, thus regulating $\mathrm{CML}$ progression. Collectively, our data reveal an earlier and unexpected role of $\beta$-arrestin1 in CML progression, as well as being a key regulator of $\mathrm{H} 4$ acetylation modification.

Both $\beta$-arrestin1 and $\beta$-arrestin2 were previously known as cytosolic signalling regulatory and scaffold proteins. The activation of GPCR recruits both $\beta$-arrestin1 and $\beta$-arrestin 2 to the cell membrane and interactions of the phosphorylated GPCR and $\beta$-arrestins induce receptor endocytosis and signal inhibition. However, accumulating evidence also revealed potential functional differences between the two $\beta$-arrestins subtypes as well as their receptor specificity. For example, previous studies demonstrated
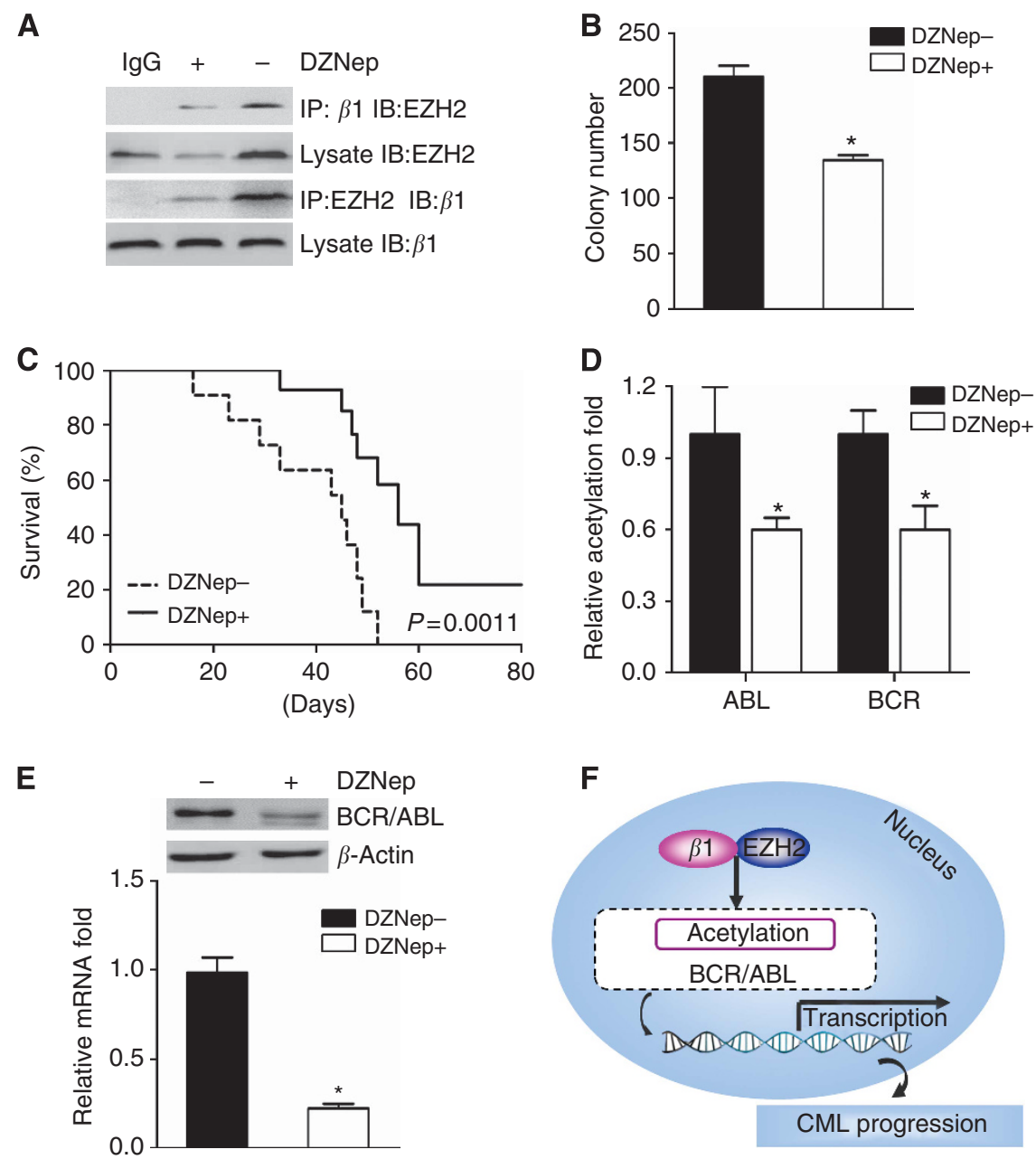

Figure 5. DZNep inhibits $\beta$-arrestin1-EZH2 binding, alters BCR/ABL gene expression and acetylation and further suppresses K562 cells progression. (A) K562 cells were pretreated with or without $2 \mu \mathrm{M}$ DZNep for $24 \mathrm{~h}$. And then Co-IP was performed to detect the expression of EZH2 and its interaction with $\beta$-arrestin1. (B) Different $K 562$ cells were cultured in a two-layer soft agar for 14 days, and the colonies ( $\geqslant 40$ cells for each) were counted. Experiments were performed triplicate at each point. (C) Stable K562-Ctrl cells were injected into the tail vein of lethally irradiated NOD/SCID mice. Ten days later, DZNep was intraperitoneally injected at a dose of $2 \mathrm{mg} \mathrm{kg}^{-1}$ daily and the survival of mice was observed. The control mice received PBS. $n=10$ each group. (D) ChIP analysis was used to determine the effects of DZNep in the acetylation of BCR and ABL. (E) The expression of $B C R / A B L$ quantified by real-time RT-PCR (lower panel) and WB (upper panel). (F) The scheme of this study. ${ }^{*} P<0.05$ vs Ctrl. 
that $\beta$-arrestin1 or $\beta$-arrestin2 has a vital role in epigenetic regulation of genes (Lefkowitz and Whalen, 2004; Kang et al, 2005; Kovacs et al, 2009; Yue et al, 2009). Although $\beta$-arrestin2 has been discovered to mediate the initiation and progression of CML (Fereshteh et al, 2012), the critical role of $\beta$-arrestin1 is still lacking. Our results of $\beta$-arrestin 1 in CML, together with previous study of $\beta$-arrestin2, provide strong evidence supporting that both $\beta$-arrestin1 and $\beta$-arrestin2 function as important regulators during CML progression. The different scenarios of $\beta$-arrestin1 and $\beta$-arrestin 2 in CML could be explained by the functional redundancy between two proteins. $\beta$-arrestin 1 seems to have a more important role during CML progression, probably due to its nuclear localisation ability (Kang et al, 2005).

Here, we reported the expression of both $\beta$-arrestin 1 and $\beta$-arrestin 2 in the different clinical phases of CML bone marrow cells in patients. Both the expression of $\beta$-arrestin 1 and $\beta$-arrestin 2 was increased in CML patients and did so in a familiar tendency. However, the enhanced level of $\beta$-arrestin1 was higher than that of $\beta$-arrestin2 in the same patient.

Meanwhile, downregulated expression of $\beta$-arrestin2 had less effect on K562 cells than in K562 cells knocked down $\beta$-arrestin1 expression (Figure 2). Together with our previous interests in $\beta$-arrestin1 in malignant tumours (Zou et al, 2008; Liu et al, 2011) we chose $\beta$-arrestin 1 for further study, and found an epigenetic regulatory role for $\beta$-arrestin1. The role of $\beta$-arrestin 2 in CML cells should be further investigated in multiple ways, and for a detailed understanding of the molecular mechanisms of CML.

Enhancer of zeste homologue 2 is one of the composed PRC2 parts in the PcG protein family. PcG proteins could bind with DNA and form DNA-protein complexes, and then transduce the signals (Saurin et al, 2001; Negre et al, 2006; Papp and Muller, 2006). EZH2 is known to be involved in the progression of prostate cancer (Varambally et al, 2002), regulation of CD11b in ATRAinduced HL-60 differentiation (Tang et al, 2009), some somatic mutations altering EZH2 (Tyr641) in follicular and diffuse large B-cell lymphomas of germinal-centre origin (Morin et al, 2010) as well as EZH2 governor B cell development through histone H3 methylation and $\mathrm{IgH}$ rearrangement ( $\mathrm{Su}$ et al, 2003). However, whether EZH2 was involved in CML was unclear. Our findings proved that EZH2 is the scaffold partner of $\beta$-arrestin 1 to form the protein complex to mediate histone $\mathrm{H} 4$ acetylation, and thus further regulate CML cells progression. Moreover, we also noticed that recruitment of EZH2 at the promoter regions of $\mathrm{BCR} / \mathrm{ABL}$ was decreased to some extent when $\beta$-arrestin1 knocked down (data not shown). The detailed binding information and mechanism of EZH2 with $\beta$-arrestin1 should be further studied.

In summary, our study unravels the function of $\beta$-arrestin 1 and further illustrates the mechanism by which $\beta$-arrestin 1 participates in epigenetic regulation in haematological malignancies. We have demonstrated that $\beta$-arrestin1 functions as an important regulator of PcG proteins, which is of great significance for PcG-mediated epigenetic regulation. Future investigations should focus on the better understanding of the mechanisms through which PcG is regulated by $\beta$-arrestin1 in the context of hematopoietic malignant diseases.

\section{ACKNOWLEDGEMENTS}

We thanked Professor Gang Pei for kindly providing lentivirus constructs, thanked Professor Tong-Chuan He, Professor Weihong Song, Dr Rongxi Yang and Dr Shan Jiang for helpful discussion and manuscript reviewing. This study was supported in part by research grants from the National Natural Science Foundation of China $(81373444,90919013)$, Natural Science Foundation of Chongqing (CSTC, 2010BA5008) and New Century Talented Program from Chinese Education Ministry (NCET-08-0932).

\section{CONFLICT OF INTEREST}

The authors declare no competing financial interests.

\section{AUTHOR CONTRIBUTIONS}

LZ and PZ designed the study, wrote, edited, and approved the final version of the manuscript. RQ, KL, XQ, and $\mathrm{XZ}$ performed the experiments and wrote the manuscript. LW helped in collecting the patients' samples.

\section{REFERENCES}

Brower-Toland B, Wacker DA, Fulbright RM, Lis JT, Kraus WL, Wang MD (2005) Specific contributions of histone tails and their acetylation to the mechanical stability of nucleosomes. J Mol Biol 346: 135-146.

Brusa G, Zuffa E, Mancini M, Benvenuti M, Calonghi N, Barbieri E, Santucci MA (2006) P210 Bcr-abl tyrosine kinase interaction with histone deacetylase 1 modifies histone $\mathrm{H} 4$ acetylation and chromatin structure of chronic myeloid leukaemia haematopoietic progenitors. Br J Haematol 132: $359-369$

Fereshteh M, Ito T, Kovacs JJ, Zhao C, Kwon HY, Tornini V, Konuma T, Chen M, Lefkowitz RJ, Reya T (2012) Beta-Arrestin2 mediates the initiation and progression of myeloid leukemia. Proc Natl Acad Sci USA 109: 12532-12537.

Ge L, Shenoy SK, Lefkowitz RJ, DeFea K (2004) Constitutive proteaseactivated receptor-2-mediated migration of MDA MB-231 breast cancer cells requires both beta-arrestin-1 and -2. J Biol Chem 279: 55419-55424.

Jia LF, Wei SB, Gan YH, Guo Y, Gong K, Mitchelson K, Cheng J, Yu GY (2013) Expression, regulation and roles of MiR-26a and MEG3 in tongue squamous cell carcinoma. Int $J$ Cancer; e-pub ahead of print 16 December 2013; doi:10.1002/ijc.28667.

Kang J, Shi Y, Xiang B, Qu B, Su W, Zhu M, Zhang M, Bao G, Wang F, Zhang X, Yang R, Fan F, Chen X, Pei G, Ma L (2005) A nuclear function of beta-arrestin1 in GPCR signaling: regulation of histone acetylation and gene transcription. Cell 123: 833-847.

Katanaev VL, Ponzielli R, Semeriva M, Tomlinson A (2005) Trimeric G protein-dependent frizzled signaling in Drosophila. Cell 120: 111-122.

Kleer CG, Cao Q, Varambally S, Shen R, Ota I, Tomlins SA, Ghosh D, Sewalt RG, Otte AP, Hayes DF, Sabel MS, Livant D, Weiss SJ, Rubin MA, Chinnaiyan AM (2003) EZH2 is a marker of aggressive breast cancer and promotes neoplastic transformation of breast epithelial cells. Proc Natl Acad Sci USA 100: 11606-11611.

Kovacs JJ, Hara MR, Davenport CL, Kim J, Lefkowitz RJ (2009) Arrestin development: emerging roles for beta-arrestins in developmental signaling pathways. Dev Cell 17: 443-458.

Lakshmikanthan V, Zou L, Kim JI, Michal A, Nie Z, Messias NC, Benovic JL, Daaka Y (2009) Identification of betaArrestin2 as a corepressor of androgen receptor signaling in prostate cancer. Proc Natl Acad Sci USA 106: 9379-9384.

Lefkowitz RJ, Shenoy SK (2005) Transduction of receptor signals by beta-arrestins. Science 308: 512-517.

Lefkowitz RJ, Whalen EJ (2004) Beta-arrestins: traffic cops of cell signaling. Curr Opin Cell Biol 16: 162-168.

Liu H, Long J, Zhang PH, Li K, Tan JJ, Sun B, Yu J, Tu ZG, Zou L (2011) Elevated beta-arrestin1 expression correlated with risk stratification in acute lymphoblastic leukemia. Int J Hematol 93: 494-501.

Lu C, Tilan JU, Everhart L, Czarnecka M, Soldin SJ, Mendu DR, Jeha D, Hanafy J, Lee CK, Sun J, Izycka-Swieszewska E, Toretsky JA, Kitlinska J (2011) Dipeptidyl peptidases as survival factors in Ewing sarcoma family of tumors: implications for tumor biology and therapy. J Biol Chem 286: 27494-27505.

Luttrell LM, Lefkowitz RJ (2002) The role of beta-arrestins in the termination and transduction of G-protein-coupled receptor signals. J Cell Sci 115: 455-465.

Miranda TB, Cortez CC, Yoo CB, Liang G, Abe M, Kelly TK, Marquez VE, Jones PA (2009) DZNep is a global histone methylation inhibitor that reactivates developmental genes not silenced by DNA methylation. Mol Cancer Ther 8: 1579-1588. 
Momparler RL, Idaghdour Y, Marquez VE, Momparler LF (2012) Synergistic antileukemic action of a combination of inhibitors of DNA methylation and histone methylation. Leuk Res 36: 1049-1054.

Morin RD, Johnson NA, Severson TM, Mungall AJ, An J, Goya R, Paul JE, Boyle M, Woolcock BW, Kuchenbauer F, Yap D, Humphries RK, Griffith OL, Shah S, Zhu H, Kimbara M, Shashkin P, Charlot JF, Tcherpakov M, Corbett R, Tam A, Varhol R, Smailus D, Moksa M, Zhao Y, Delaney A, Qian H, Birol I, Schein J, Moore R, Holt R, Horsman DE, Connors JM, Jones S, Aparicio S, Hirst M, Gascoyne RD, Marra MA (2010) Somatic mutations altering EZH2 (Tyr641) in follicular and diffuse large B-cell lymphomas of germinal-center origin. Nat Genet 42: 181-185.

Negre N, Hennetin J, Sun LV, Lavrov S, Bellis M, White KP, Cavalli G (2006) Chromosomal distribution of PcG proteins during Drosophila development. PLoS Biol 4: e170.

Neviani P, Santhanam R, Trotta R, Notari M, Blaser BW, Liu S, Mao H, Chang JS, Galietta A, Uttam A, Roy DC, Valtieri M, Bruner-Klisovic R, Caligiuri MA, Bloomfield CD, Marcucci G, Perrotti D (2005) The tumor suppressor PP2A is functionally inactivated in blast crisis CML through the inhibitory activity of the BCR/ABL-regulated SET protein. Cancer Cell 8: $355-368$.

Papp B, Muller J (2006) Histone trimethylation and the maintenance of transcriptional $\mathrm{ON}$ and OFF states by trxG and PcG proteins. Genes Dev 20: 2041-2054.

Parruti G, Peracchia F, Sallese M, Ambrosini G, Masini M, Rotilio D, De Blasi A (1993) Molecular analysis of human beta-arrestin-1: cloning, tissue distribution, and regulation of expression. Identification of two isoforms generated by alternative splicing. J Biol Chem 268: 9753-9761.

Raghuwanshi SK, Nasser MW, Chen X, Strieter RM, Richardson RM (2008) Depletion of beta-arrestin-2 promotes tumor growth and angiogenesis in a murine model of lung cancer. J Immunol 180: 5699-5706.

Roman-Gomez J, Jimenez-Velasco A, Agirre X, Castillejo JA, Navarro G, San Jose-Eneriz E, Garate L, Cordeu L, Cervantes F, Prosper F, Heiniger A, Torres A (2007) Epigenetic regulation of human cancer/testis antigen gene, HAGE, in chronic myeloid leukemia. Haematologica 92: 153-162.

Rosano L, Cianfrocca R, Masi S, Spinella F, Di Castro V, Biroccio A, Salvati E, Nicotra MR, Natali PG, Bagnato A (2009) Beta-arrestin links endothelin A receptor to beta-catenin signaling to induce ovarian cancer cell invasion and metastasis. Proc Natl Acad Sci USA 106: 2806-2811.

Saurin AJ, Shao Z, Erdjument-Bromage H, Tempst P, Kingston RE (2001) A Drosophila Polycomb group complex includes Zeste and dTAFII proteins. Nature 412: 655-660.

Shi Y, Feng Y, Kang J, Liu C, Li Z, Li D, Cao W, Qiu J, Guo Z, Bi E, Zang L, Lu C, Zhang JZ, Pei G (2007) Critical regulation of CD4 + T cell survival and autoimmunity by beta-arrestin 1. Nat Immunol 8: 817-824.
Strahl BD, Allis CD (2000) The language of covalent histone modifications. Nature 403: 41-45.

Strathdee G, Sim A, Soutar R, Holyoake TL, Brown R (2007) HOXA5 is targeted by cell-type-specific CpG island methylation in normal cells and during the development of acute myeloid leukaemia. Carcinogenesis 28: 299-309.

Su IH, Basavaraj A, Krutchinsky AN, Hobert O, Ullrich A, Chait BT, Tarakhovsky A (2003) Ezh2 controls B cell development through histone H3 methylation and Igh rearrangement. Nat Immunol 4: 124-131.

Tan J, Yang X, Zhuang L, Jiang X, Chen W, Lee PL, Karuturi RK, Tan PB, Liu ET, Yu Q (2007) Pharmacologic disruption of Polycomb-repressive complex 2-mediated gene repression selectively induces apoptosis in cancer cells. Genes Dev 21: 1050-1063.

Tang H, Chen F, Tan Q, Tan S, Liu L, Zhang F (2009) Regulation of CD11b transcription by decreasing PRC2 and increased acH4 level during ATRA-induced HL-60 differentiation. Acta Biochim Biophys Sin (Shanghai) 41: 588-593.

Varambally S, Dhanasekaran SM, Zhou M, Barrette TR, Kumar-Sinha C, Sanda MG, Ghosh D, Pienta KJ, Sewalt RG, Otte AP, Rubin MA, Chinnaiyan AM (2002) The polycomb group protein EZH2 is involved in progression of prostate cancer. Nature 419: 624-629.

Wang P, Gao H, Ni Y, Wang B, Wu Y, Ji L, Qin L, Ma L, Pei G (2003) Beta-arrestin 2 functions as a G-protein-coupled receptor-activated regulator of oncoprotein Mdm2. J Biol Chem 278: 6363-6370.

Wei Y, Chen YH, Li LY, Lang J, Yeh SP, Shi B, Yang CC, Yang JY, Lin CY, Lai CC, Hung MC (2011) CDK1-dependent phosphorylation of EZH2 suppresses methylation of $\mathrm{H} 3 \mathrm{~K} 27$ and promotes osteogenic differentiation of human mesenchymal stem cells. Nat Cell Biol 13: 87-94.

Workman P, Aboagye EO, Balkwill F, Balmain A, Bruder G, Chaplin DJ, Double JA, Everitt J, Farningham DA, Glennie MJ, Kelland LR, Robinson V, Stratford IJ, Tozer GM, Watson S, Wedge SR, Eccles SA (2010) Guidelines for the welfare and use of animals in cancer research. Br J Cancer 102: 1555-1577.

Yue R, Kang J, Zhao C, Hu W, Tang Y, Liu X, Pei G (2009) Beta-arrestin1 regulates zebrafish hematopoiesis through binding to YY1 and relieving polycomb group repression. Cell 139: 535-546.

Zou L, Yang R, Chai J, Pei G (2008) Rapid xenograft tumor progression in beta-arrestin1 transgenic mice due to enhanced tumor angiogenesis. FASEB J 22: 355-364.

This work is published under the standard license to publish agreement. After 12 months the work will become freely available and the license terms will switch to a Creative Commons AttributionNonCommercial-Share Alike 3.0 Unported License.

Supplementary Information accompanies this paper on British Journal of Cancer website (http://www.nature.com/bjc) 